\title{
Response style and severity and chronicity of depressive disorders in primary health care
}

\section{Riihimaki, K.}

2016-03

Riihimaki , K, Vuorilehto , M , Jylhä , P \& Isometsa , E 2016, ' Response style and severity and chronicity of depressive disorders in primary health care ' , European Psychiatry , vol. 33 , pp. 1-8 . https://doi.org/10.1016/j.eurpsy.2015.12.002

http://hdl.handle.net/10138/223874

https://doi.org/10.1016/j.eurpsy.2015.12.002

publishedVersion

Downloaded from Helda, University of Helsinki institutional repository.

This is an electronic reprint of the original article.

This reprint may differ from the original in pagination and typographic detail.

Please cite the original version. 
Original article

\title{
Response style and severity and chronicity of depressive disorders in primary health care
}

\author{
K. Riihimäki ${ }^{\text {a,b }}$, M. Vuorilehto ${ }^{a, c}$, P. Jylhä ${ }^{a, c}$, E. Isometsä a,c,* \\ ${ }^{a}$ Mental Health Research Unit, National Institute for Health and Welfare, Helsinki, Finland \\ ${ }^{\mathrm{b}}$ Health Care and Social Services, City of Järvenpää, PL 41, 04401 Järvenpää, Finland \\ ${ }^{\mathrm{c}}$ Department of Psychiatry, University of Helsinki and Helsinki University Hospital, P.O.Box 900, 00029 HUS, Helsinki, Finland
}

\section{A R T I C L E I N F O}

\section{Article history:}

Received 7 October 2015

Received in revised form 4 December 2015

Accepted 6 December 2015

Available online 6 February 2016

\section{Keywords:}

Depression

Response style

Rumination

Neuroticism

Comorbidity

Primary care

\begin{abstract}
A B S T R A C T
Background: Response styles theory of depression postulates that rumination is a central factor in occurrence, severity and maintaining of depression. High neuroticism has been associated with tendency to ruminate. We investigated associations of response styles and neuroticism with severity and chronicity of depression in a primary care cohort study.

Methods: In the Vantaa Primary Care Depression Study, a stratified random sample of 1119 adult patients was screened for depression using the Prime-MD. Depressive and comorbid psychiatric disorders were diagnosed using SCID-I/P and SCID-II interviews. Of the 137 patients with depressive disorders, 82\% completed the prospective five-year follow-up with a graphic life chart enabling evaluation of the longitudinal course of episodes. Neuroticism was measured with the Eysenck Personality Inventory (EPIQ). Response styles were investigated at five years using the Response Styles Questionnaire (RSQ-43). Results: At five years, rumination correlated significantly with scores of Hamilton Depression Rating Scale $(r=0.54)$, Beck Depression Inventory $(r=0.61)$, Beck Anxiety Inventory $(r=0.50)$, Beck Hopelessness Scale $(r=0.51)$ and Neuroticism $(r=0.58)$. Rumination correlated also with proportion of follow-up time spent depressed $(r=0.38)$. In multivariate regression, high rumination was significantly predicted by current depressive symptoms and neuroticism, but not by anxiety symptoms or preceding duration of depressive episodes.

Conclusions: Among primary care patients with depression, rumination correlated with current severity of depressive symptoms, but the association with preceding episode duration remained uncertain. The association between neuroticism and rumination was strong. The findings are consistent with rumination as a state-related phenomenon, which is also strongly intertwined with traits predisposing to depression.
\end{abstract}

(c) 2015 Elsevier Masson SAS. All rights reserved.

\section{Introduction}

Response styles theory of depression postulates that the ways an individual responds to depressed mood influences the occurrence and severity of depression, but the influence of rumination on the duration of depression has remained unclear [1-3]. The postulated response styles comprise rumination, distraction, problem-solving and dangerous activities. Rumination is a characteristic response to distress; a perseverant cognitive process of focusing passively,

\footnotetext{
* Corresponding author at: Department of Psychiatry, Faculty of Medicine, University of Helsinki, P.O. Box 22, 00014 Helsinki, Finland. Tel.: +358 947163728 ; fax: +358947163735.

E-mail address: erkki.isometsa@hus.fi (E. Isometsä).
}

repetitively and negatively on symptoms past and present, resulting in emotional distress. Rumination has been associated with female gender [4], and as a putatively transdiagnostic process, also with numerous psychiatric disorders besides depression, particularly anxiety [5-7]. Rumination is reported to be composed of different factors, such as brooding and pondering or reflection [8-11], but findings among depressed patients have been inconsistent [12]. Negative affectivity or neuroticism have been found to be correlated with rumination [12].

Rumination may be, at least in part, an expression of underlying high neuroticism. Neuroticism is characterized by proneness to anxiety, emotional instability and self-consciousness, whereas extraversion involves positive emotionality, energy and dominance [13]. They are to some degree inherited traits [13]. Neuroticism is 
believed to reflect a stable disposition involving specific biological and psychological mechanisms that produce its robust association with psychopathology $[14,15]$. High neuroticism has been shown to be a risk factor or indicator for MDD in prospective epidemiological twin [16,17], general population [18] and clinical [19-22] studies. Moreover, current mood has been found to influence neuroticism $[22,23]$. In contrast, the findings regarding to extraversion are more controversial [16,17,19-22,24,25].

Response styles have been investigated mostly either in nondepressed populations [6,7,26,27], especially students [2,28,29], or in bereaved individuals [30,31], with only few longitudinal prospective studies $[26,29]$. There are some clinical studies, both cross-sectional [32,33] and longitudinal [24,34-36], including a long-term study of inpatients with major depressive disorder (MDD) $[37,38]$. In a clinical trial among primary care patients with minor depression and dysthymia, depressive symptoms and rumination decreased over time but distraction did not; rumination and distraction were associated with more depressive symptoms at the conclusion of treatment [39]. Overall, the empirical status of the response styles theory of depression varies by type of response style. The association between rumination and depressive symptoms seems strong in non-clinical samples, but appears less consistent in clinically depressed patients [27,34]. The association between distraction and depression is inconsistent $[29,40]$. Problem-solving and dangerous activities have been investigated relatively seldom. Regarding associations with personality, longitudinal research among depressed patients is scarce. Despite research pertaining to relationships between response styles and personality with depressive symptoms, a need for long-term clinical studies among depressed patients exists.

The original response styles theory [1,2] postulates a longer duration of depression among individuals with a ruminative response style. To test this hypothesis, duration of depression episodes must be measured. To our knowledge, response styles have not been investigated with life-chart methodology among depressive patients. We investigated the influence of response styles in a naturalistic prospective Finnish cohort of primary care patients with depressive disorders. The study was limited by having measures of response style available only at the end of follow-up, but nevertheless allowed cross-sectional and retrospective analyses. We hypothesized that rumination would correlate, first, with both current severity and retrospective duration of major depressive episodes (MDEs) as well as with concurrent anxiety, gender and neuroticism, and, second, with other clinical and psychosocial factors. We also explored the correlation of the other response styles with outcome of depression and other clinical and psychosocial factors.

\section{Material and methods}

\subsection{Patients and procedures}

The Vantaa Primary Care Depression Study (PC-VDS) was approved by the pertinent Ethics Committee in 2001. Based on stratified sampling within the city of Vantaa, Finland, altogether 373 of 1119 general practitioners' patients aged 20-69 years screened with the Primary Care Evaluation of Mental Disorders (PRIME-MD) had a positive screen for depression [41]. The presence of at least one core symptom of MDD according to the Structured Clinical Interview for DSM-IV Axis I Disorders (SCID I/P) was confirmed by telephone. All of the 175 potentially eligible patients were interviewed face-to-face using the SCID I/P with psychotic screen. Inclusion criteria were current:

- MDD;

- dysthymia;
- subsyndromal MDD with two to four depression symptoms (minimum one core symptom) and lifetime MDD;

- and minor depression otherwise similar to subsyndromal MDD, but without MDD history.

Patients who refused to participate (15\%) did not differ significantly in age or gender from those who consented. The diagnostic reliability for current depressive disorder diagnoses was excellent (kappa $=1.0)$.

The final study sample comprised 137 patients. Current and lifetime psychiatric disorders were assessed with SCID-I/P and SCID-II interviews. In addition to the face-to-face interviews, observed and self-report scales and all medical and psychiatric records were used to assess retrospective and prospective course of depression, comorbid disorders and psychosocial and socioeconomic factors [41]. Scales comprised Hamilton Rating Scale for Depression (HAMD), Beck Depression Inventory (BDI), Beck Anxiety Inventory (BAI), Beck Hopelessness Scale (HS), Social and Occupational Functioning Assessment Scale for DSM-IV (SOFAS) and Scale for Suicidal Ideation (SSI).

After baseline, patients were prospectively investigated at 3 , 6 and 18 months and 5 years [42]. The 5-year investigation included the same diagnostic interviews, scales and medical and psychiatric records as the baseline investigation. Exact timing and duration of episodes of depression and substance abuse were examined by gathering all available data from symptom ratings and from medical and psychiatric records and by reviewing with the patient all information from the follow-up period using important life events in order to improve the accuracy of the assessment, a best estimate of which was then integrated into a graphic life-chart. Dropouts (18\%) did not differ from participants in age, gender or baseline depression severity [42]. Of patients followed for 5 years, 87\% (97/111) fulfilled the Response Styles Questionnaire (RSQ); they were more often females, younger and less depressed than those who didńt. Baseline and 5-year patient characteristics are shown in Table 1.

\subsection{Measures of response style and personality}

Response styles were measured with Response Styles Questionnaire (RSQ), which is administered to assess tendencies to react in response to symptoms of negative emotion [43]. The RSQ-43 includes rumination scale (24 items), distraction scale (11 items), problem-solving scale (4 items) and dangerous activities scale ( 4 items). The items are measured on a 4-point Likert-type scale. The ruminative response scale consists of items that assess responses to dysphoric mood focused on self, symptoms, or possible consequences and causes of mood, and also includes behavioural responses. Regarding rumination, we analysed separately the most commonly used scale including 22 items (rumination-22), the short RSQ (rumination-10; those 10 items that have had the highest itemtotal correlations with the full-scale rumination and with BDI), and brooding ( 5 items) and pondering (3 items) subscales [9]. With permission by the developer (Nolen-Hoeksema, 2007, personal correspondence), we translated the questionnaire into Finnish with the standard method including back-translation. Internal consistency of the scales was measured with Cronbach's alpha and generally found to be good to excellent: alpha for rumination$24=0.94$, rumination- $22=0.93$, rumination $-10=0.90$, brooding $=0.80$, pondering $=0.69$, distraction $=0.82$, problem-solving $=0.71$, dangerous activities $=0.37$ ( $=0.60$ without item 37 ).

Personality was assessed with Eysenck Personality Inventory, form B (EPI) [44] at baseline and at the 18-month follow-up and with EPI-Q [45] at the 5-year follow-up. EPI-Q is a short measure based on EPI and comprises 18 items, 9 of the EPI's original 24 neuroticism items and 9 of the original 24 extraversion items. 
Table 1

Characteristics of patients in the Vantaa Primary Care Depression Study $(n=97)$.

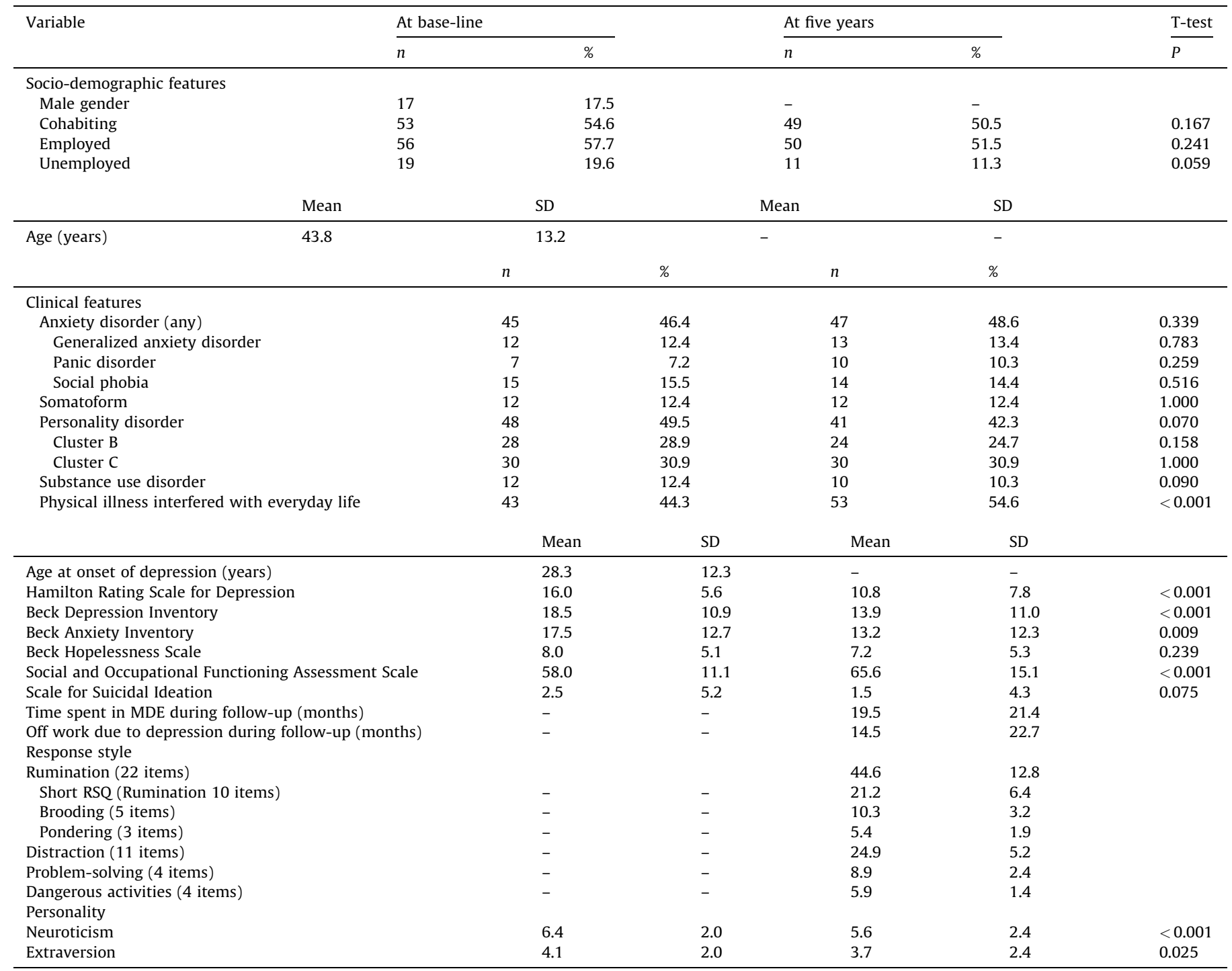

The correlation between EPI and EPI-Q was good at baseline and at 18months for neuroticism $(r=0.89, P<0.001$, and $r=0.91, P<0.001$, respectively) and extraversion $(r=0.81, P<0.001$, and $r=0.89$, $P<0.001$, respectively). Cronbach's alphas for EPI-Q questions were also good for neuroticism and extraversion at all 3 time-points (alpha at baseline $=0.65$ and 0.67 ; at 18 months $=0.72$ and 0.72 ; and at 5 years $=0.76$ and 0.71 , respectively).

The correlation between rumination at 5 years and neuroticism was consistent irrespective of time-point of measurement of neuroticism $(r=0.52, r=0.45$ and $r=0.58 ; P<0.001)$, which allowed us to use rumination as an independent variable in linear regression analyses. In univariate linear regression (adjusted for age, gender and follow-up time), neuroticism at baseline ( $\beta=3.559$, $P<0.001)$, at 18 months $(\beta=2.749, P<0.001)$, and at 5 years ( $\beta=3.486, P<0.001)$ were equal predictors of rumination. The relationship persisted after controlling for current HAMD.

\subsection{Statistical methods}

Between-group comparisons were computed using ANOVA. Bivariate correlational analyses and linear regression models were used to analyse associations of different variables with response styles. In the final multivariate models, the non-significant variables were omitted. Models were adjusted for age, gender and follow-up time, and, when appropriate, also for the severity of depression (HAMD) and the duration of MDEs. Regression analysis allows the impact of the severity and duration of depression to be controlled because response style and depression are often highly correlated.

To estimate the influence of current depressive state on variations in response style, we conducted a separate sensitivity analysis of a subgroup of patients in full remission or in MDE at 5 years and examined the potential influence of the duration of the last full remission.

\section{Results}

\subsection{Rumination and depression}

Rumination total score was significantly associated with the current clinical state of depression (full remission, partial remission or MDE) cross-sectional at 5 years (Table 2). More specifically, all of the brooding $(r=0.31-0.57 ; P=<0.001-0.021)$ 
Table 2

Response styles in full remission, in partial remission and in MDE at five years in the Vantaa Primary Care Depression Study ( $n=97$ ).

\begin{tabular}{|c|c|c|c|c|c|c|c|}
\hline & \multicolumn{2}{|c|}{ Full remission $n=46$} & \multicolumn{2}{|c|}{$\begin{array}{l}\text { Partial remission } \\
n=33\end{array}$} & \multicolumn{2}{|c|}{ MDE $n=18$} & \multirow[t]{2}{*}{$P$} \\
\hline & Mean & SD & Mean & SD & Mean & SD & \\
\hline \multicolumn{8}{|l|}{ Response style } \\
\hline Rumination & 39.8 & 10.8 & 44.2 & 9.9 & 57.4 & 12.8 & $<0.001$ \\
\hline Rumination-10 & 18.4 & 5.0 & 21.6 & 5.2 & 28.3 & 6.6 & $<0.001$ \\
\hline Brooding & 9.3 & 2.7 & 9.8 & 2.9 & 13.5 & 3.0 & $<0.001$ \\
\hline Pondering & 5.2 & 1.9 & 5.2 & 1.9 & 6.0 & 2.0 & 0.341 \\
\hline Distraction & 26.1 & 4.2 & 24.0 & 5.5 & 23.6 & 7.9 & 0.106 \\
\hline Problem-solving & 9.3 & 2.4 & 8.8 & 2.5 & 8.0 & 2.3 & 0.171 \\
\hline Dangerous activities & 5.6 & 1.1 & 6.1 & 1.7 & 6.8 & 1.6 & 0.010 \\
\hline \multicolumn{8}{|l|}{ Psychiatric symptoms } \\
\hline Beck Depression Inventory & 6.7 & 4.5 & 15.0 & 6.6 & 31.1 & 9.6 & $<0.001$ \\
\hline Hamilton Rating Scale for Depression & 5.2 & 2.9 & 12.2 & 4.6 & 23.1 & 5.1 & $<0.001$ \\
\hline Beck Anxiety Inventory & 6.7 & 5.9 & 14.3 & 10.0 & 28.2 & 14.9 & $<0.001$ \\
\hline \multicolumn{8}{|l|}{ Personality } \\
\hline Neuroticism & 4.7 & 2.6 & 6.1 & 2.0 & 7.4 & 1.6 & 0.001 \\
\hline Extraversion & 3.9 & 2.6 & 3.3 & 2.4 & 3.67 & 2.2 & 0.564 \\
\hline
\end{tabular}

ANOVA: analysis of variance.

but none of the pondering $(r=0.10-0.14 ; P=0.171-0.353)$ items were significantly associated with the current state of depression (HAMD scores). Table 3 shows, that the tendency to ruminate correlated with current severity of depressive or anxiety symptoms, duration of depression and neuroticism. The association of total scores of rumination with those of HAMD is depicted in Fig. 1.

In the small subgroup of eight patients who spent the entire 5year follow-up in MDEs, the mean rumination scores crosssectional at 5 years were markedly higher $(65.8$, SD 13.0$)$ than those of other patients (43.2, SD 10.9; $P<0.001)$. Within the subgroup of 46 patients fully remitted at 5 years, the same tendencies remained mostly significant within the limited range of none to mild symptoms present (Table 4). Importantly, however, within this subgroup rumination had no significant correlation with the retrospective duration of time spent in MDEs during the follow-up or with duration of full remission immediately before the 5-year interview.

In univariate linear regression analyses with time spent in MDEs during follow-up as the dependent variable, the association with rumination was significant $(B=0.674, \beta=0.405,95 \% \mathrm{CI}$ : $0.362-0.986 ; P<0.001)$. However, in multivariate analyses including baseline variables HAMD ( $B=1.167, \beta=0.308,95 \% \mathrm{CI}$ :

Table 3

Bivariate correlations between response styles and other variables in the Vantaa Primary Care Depression Study at five years ( $n=97$ ).

\begin{tabular}{|c|c|c|c|c|c|c|c|}
\hline & Rumination & Rumination-10 & Brooding & Pondering & Distraction & Problem-solving & $\begin{array}{l}\text { Dangerous } \\
\text { activities }\end{array}$ \\
\hline \multicolumn{8}{|l|}{ Response styles } \\
\hline Rumination & - & $0.938^{* *}$ & $0.861^{* *}$ & $0.717^{* *}$ & -0.003 & $-0.226^{*}$ & $0.502^{* *}$ \\
\hline Rumination-10 & $0.938^{* *}$ & - & $0.861^{* *}$ & $0.522^{* *}$ & -0.150 & $-0.314^{* * *}$ & $0.515^{* *}$ \\
\hline Brooding & $0.861^{* *}$ & $0.861^{* *}$ & - & $0.498^{* *}$ & 0.068 & -0.116 & $0.483^{* *}$ \\
\hline Pondering & $0.717^{*}$ & $0.522^{* *}$ & $0.498^{* *}$ & - & 0.094 & -0.157 & $0.285^{* *}$ \\
\hline Distraction & -0.003 & -0.150 & 0.068 & 0.094 & - & $0.639^{* *}$ & -0.145 \\
\hline Problem-solving & $-0.226^{*}$ & $-0.314^{* *}$ & -0.116 & -0.157 & $0.639^{* *}$ & - & -0.163 \\
\hline Dangerous activities & $0.502^{* *}$ & $0.515^{* *}$ & $0.483^{* *}$ & $0.285^{* *}$ & -0.145 & -0.163 & - \\
\hline \multicolumn{8}{|l|}{ Symptom variables } \\
\hline Anxiety disorder 5y & $0.341^{* *}$ & $0.285^{* *}$ & $0.308^{* *}$ & 0.150 & -0.047 & -0.154 & $0.255^{*}$ \\
\hline Personality disorder & $0.248^{*}$ & $0.324^{* *}$ & $0.366^{* *}$ & 0.161 & -0.074 & -0.177 & $0.282^{* *}$ \\
\hline Cluster C & $0.240^{*}$ & $0.269^{* * *}$ & $0.340^{* * *}$ & 0.118 & -0.144 & -0.168 & 0.110 \\
\hline Beck Depression Inventory BL & $0.445^{* *}$ & $0.468^{* *}$ & $0.400^{* *}$ & $0.283^{* *}$ & -0.027 & -0.163 & $0.242^{*}$ \\
\hline Beck Depression Inventory 5y & $0.611^{* *}$ & $0.636^{* *}$ & $0.575^{* *}$ & $0.242^{*}$ & -0.165 & $-0.307^{* *}$ & $0.397^{* *}$ \\
\hline Hamilton Rating Scale for Depression 5y & $0.537^{* *}$ & $0.603^{* *}$ & $0.505^{* *}$ & 0.150 & -0.181 & $-0.241^{*}$ & $0.327^{* *}$ \\
\hline Beck Anxiety Inventory $5 y$ & $0.496^{* *}$ & $0.520^{* *}$ & $0.425^{* *}$ & 0.193 & -0.112 & $-0.209^{*}$ & $0.418^{* *}$ \\
\hline Beck Hopelessness Scale 5y & $0.511^{* *}$ & $0.558^{* *}$ & $0.472^{* *}$ & $0.262^{*}$ & -0.234 & $-0.359^{* *}$ & $0.386^{* *}$ \\
\hline Scale for Suicidal Ideation $5 y$ & $0.358^{* *}$ & $0.324^{* *}$ & $0.379^{* *}$ & $0.202^{*}$ & -0.033 & -0.119 & $0.278^{* *}$ \\
\hline Social and Occupational Functioning Assessment Scale 5y & $-0.474^{* *}$ & $-0.5566^{* *}$ & $-0.434^{* * *}$ & -0.190 & 0.141 & $0.289^{* * *}$ & $-0.266^{* *}$ \\
\hline Substance use disorder $5 y$ & $0.304^{* *}$ & $0.305^{* * *}$ & $0.251^{*}$ & 0.183 & -0.017 & -0.179 & $0.451^{* *}$ \\
\hline Age at onset of depression & -0.119 & $-0.212^{*}$ & $0.228^{*}$ & -0.085 & 0.017 & -0.002 & $-0.231^{*}$ \\
\hline Time spent in MDEs BL-5y & $0.376^{* *}$ & $0.303^{* *}$ & $0.404^{* *}$ & 0.122 & -0.015 & -0.203 & $0.217^{*}$ \\
\hline Recurrences BL-5y & $0.232^{*}$ & $0.213^{*}$ & $0.232^{*}$ & 0.114 & 0.019 & -0.069 & -0.005 \\
\hline Time spent unable to work BL-5y & 0.181 & $0.209^{*}$ & 0.202 & 0.074 & -0.085 & -0.066 & 0.027 \\
\hline \multicolumn{8}{|l|}{ Personality } \\
\hline Neuroticism 5y & $0.584^{* *}$ & $0.630^{* *}$ & $0.526^{* *}$ & $0.301^{* *}$ & -0.089 & $-0.299^{* *}$ & $0.367^{* *}$ \\
\hline Extraversion $5 y$ & $-0.231^{*}$ & $-0.260^{*}$ & -0.193 & -0.126 & $0.290^{* *}$ & $0.392^{* *}$ & -0.099 \\
\hline
\end{tabular}

BL: at baseline; 5y: at five years; BL-5y: during the five-year follow-up.

" $P<0.050$

$P<0.010$ 


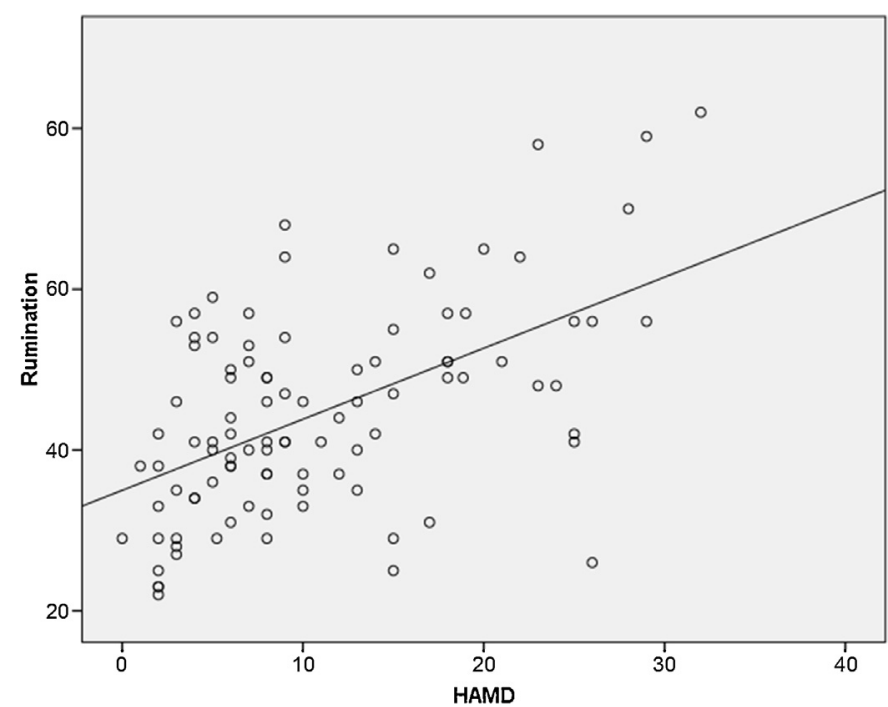

Fig. 1. Rumination and Hamilton Rating Scale for Depression (HAMD) at five years in the Vantaa Primary Care Depression Study $(n=97)$.

$0.455-1.879 ; P=0.002)$, substance use disorder $(B=23.921$, $\beta=0.371,95 \% \mathrm{CI}: 11.875-35.967 ; P<0.001)$ and rumination as independent variables, rumination lost significance $(P=0.270)$.

In analyses predicting rumination at five years, HAMD at baseline and time spent in MDEs during follow-up were significant predictors. In univariate linear regression analyses predicting rumination as the dependent variable, both HAMD $(B=1.001$, $\beta=0.440,95 \% \mathrm{CI}: 0.567-1.434 ; P<0.001)$ and time spent in MDEs during follow-up $(B=0.248, \beta=0.413,95 \% \mathrm{CI}$ : $0.133-0.362$; $P<0.001$ ) were significant predictors. In multivariate analyses of baseline variables, BAI $(B=0.374, \beta=0.376,95 \% \mathrm{CI}$ : $0.191-$ $0.558 ; P<0.001)$ and substance use disorder $(B=12.254$, $\beta=0.326$, 95\% CI: 5.246-19.263; $P<0.001)$ predicted rumination.
Table 5

Multivariate linear regression for rumination among depressed primary care patients $(n=97)$.

\begin{tabular}{lllll}
\hline & $\mathrm{B}$ & $\beta$ & $95 \% \mathrm{CI}$ & $P$ \\
\hline Age & 0.028 & 0.030 & $-0.139 ; 0.195$ & 0.741 \\
$\begin{array}{l}\text { Gender } \\
\text { Follow-up time }\end{array}$ & -2.396 & 0.075 & $-3.403 ; 8.194$ & 0.413 \\
$\begin{array}{c}\text { Time spent in } \\
\quad \text { MDEs during follow-up }\end{array}$ & -0.007 & -0.060 & $-0.028 ; 0.015$ & 0.531 \\
$\begin{array}{c}\text { Beck Depression Inventory, } \\
\quad \begin{array}{l}\text { at five years } \\
\text { Beck Anxiety Inventory, }\end{array}\end{array}$ & 0.502 & -0.419 & $0.177 ; 0.826$ & 0.003 \\
$\quad \begin{array}{l}\text { at five years } \\
\text { Neuroticism, at five years }\end{array}$ & 2.312 & 0.452 & $1.217 ; 3.408$ & $<0.0000$ \\
\hline
\end{tabular}

However, in multivariate linear regression analyses including concurrent BDI, BAI and neuroticism as independent variables, all of these factors were significantly associated with the dependent variable rumination, but duration of time ill during the follow-up was not (Table 5).

\subsection{Rumination, neuroticism, and depression}

Regarding associations between personality, rumination and depression, we found that the correlation between neuroticism and rumination was significant $(r=0.58, P<0.001)$, as was the correlation between rumination and depression (HAMD) $(r=0.54$, $P<0.001)$. However, in correlational analyses, the correlation between neuroticism and depression $(r=0.48, P<0.001)$ disappeared when controlled for rumination $(r=0.27, P=0.012)$. In univariate linear regression, adjusted with age and gender, neuroticism predicted rumination ( $B=0.113, \beta=0.579,95 \% \mathrm{CI}$ : 0.079-0.147; $P<0.001, \mathrm{SE}=0.017$ ) and depression (HAMD) $(B=1.567, \beta=0.513,95 \% \mathrm{CI}: 0.969-2.165 ; P<0.001, \mathrm{SE}=0.301)$. In multivariate regression model, neuroticism $(B=1.036$, $\beta=0.339,95 \% \mathrm{CI}: 0.316-1.755 ; P=0.005, \mathrm{SE}=0.069)$ plus rumination $(B=0.172, \quad \beta=0.288,95 \% \mathrm{CI}$ : $0.034-0.310 ; P=0.015$, $\mathrm{SE}=0.316)$ predicted depression.

Table 4

Bivariate correlations between response styles and other variables in the Vantaa Primary Care Depression Study among patients in full remission at five years ( $n=46$ ).

\begin{tabular}{|c|c|c|c|c|c|c|c|}
\hline & Rumination & Rumination-10 & Brooding & Pondering & Distraction & Problem-solving & $\begin{array}{l}\text { Dangerous } \\
\text { activities }\end{array}$ \\
\hline \multicolumn{8}{|l|}{ Response style } \\
\hline Rumination & & $0.947^{* *}$ & $0.850^{* *}$ & $0.789^{* *}$ & 0.111 & -0.197 & -0.197 \\
\hline Rumination-10 & $0.947^{* *}$ & & $0.820^{* *}$ & $0.676^{* *}$ & 0.034 & -0.296 & 0.278 \\
\hline Brooding & $0.850^{* *}$ & $0.820^{* *}$ & & $0.612^{* *}$ & 0.252 & -0.085 & 0.230 \\
\hline Pondering & $0.789^{* *}$ & $0.676^{* * *}$ & $0.612^{* *}$ & & 0.103 & -0.178 & $0.310^{*}$ \\
\hline Distraction & 0.111 & 0.034 & 0.252 & 0.103 & & $0.548^{* *}$ & 0.200 \\
\hline Problem-solving & -0.197 & -0.296 & -0.085 & -0.178 & $0.548^{* *}$ & & -0.162 \\
\hline Dangerous activities & -0.197 & 0.278 & 0.230 & $0.310^{*}$ & -0.200 & -0.162 & \\
\hline \multicolumn{8}{|l|}{ Symptom variables } \\
\hline Beck Depression Inventory & $0.596^{* *}$ & $0.580^{* * *}$ & $0.537^{* *}$ & $0.538^{* *}$ & 0.170 & $-0.300^{*}$ & $0.406^{* *}$ \\
\hline Hamilton Rating Scale for Depression & $0.435^{* *}$ & $0.462^{* *}$ & 0.211 & $0.333^{*}$ & 0.114 & -0.086 & 0.131 \\
\hline Beck Anxiety Inventory & $0.307^{*}$ & $0.309^{*}$ & 0.157 & 0.268 & 0.032 & 0.093 & $0.425^{* *}$ \\
\hline Beck Hopelessness Scale & $0.382^{* *}$ & $0.313^{*}$ & 0.231 & $0.569^{* *}$ & 0.021 & $-0.338^{*}$ & 0.288 \\
\hline $\begin{array}{l}\text { Social and Occupational } \\
\text { Functioning Assessment Scale }\end{array}$ & -0.260 & $-0.301^{*}$ & -0.139 & -0.212 & -0.177 & 0.225 & 0.041 \\
\hline Scale for Suicidal Ideation & 0.227 & 0.108 & 0.260 & $0.536^{*}$ & 0.268 & 0.168 & 0.062 \\
\hline Time spent in MDEs BL-5y & 0.074 & 0.113 & 0.073 & -0.058 & 0.243 & 0.099 & -0.107 \\
\hline Duration of last full remission & -0.061 & -0.120 & -0.098 & 0.005 & -0.193 & -0.051 & 0.149 \\
\hline \multicolumn{8}{|l|}{ Personality } \\
\hline Neuroticism & $0.533^{* *}$ & $0.584^{* *}$ & $0.418^{* *}$ & 0.307 & -0.090 & $-0.335^{*}$ & 0.299 \\
\hline Extraversion & $-0.343^{*}$ & $-0.369^{*}$ & -0.250 & -0.222 & -0.030 & $0.308^{*}$ & -0.138 \\
\hline
\end{tabular}

BL-5y: during the five-year follow-up.

${ }^{*} P<0.050$.

$P<0.010$ 


\subsection{Gender differences}

Overall, gender differences in response styles were small. A significant gender difference emerged only in the problem-solving scale, with females scoring higher than males (mean 9.14, SD 2.4 vs. mean 7.60 , SD 2.2; $P=0.025$; ANOVA).

\subsection{Distraction, problem-solving and dangerous activities}

Dangerous activities was associated significantly with the current state of depression cross-sectional at 5 years (Table 2). The tendency towards dangerous activities increased with symptoms and duration of depression and neuroticism, whereas the reverse was true for distraction and problem-solving (Table 3 ). In univariate linear regression analyses, problem-solving $(\beta=-0.217,95 \% \mathrm{CI}:-3.620 ;-0.059 ; P=0.043)$ and dangerous activities $(\beta=0.302,95 \% \mathrm{CI}: 1.433-7.068 ; P=0.004)$ but not distraction $(\beta=-0.094,95 \% \mathrm{CI}:-1.217 ; 0.447 ; P=0.360)$ were significantly associated with the time spent in MDEs during followup. However, in multivariate analyses they lost significance.

\section{Discussion}

In following up depressive primary care patients for five years, we found that the tendency to ruminate at endpoint was strongly related to the current severity of depressive and also anxiety symptoms. While ruminative response style was also moderately strongly related to duration of time spent in depressive episodes during the preceding five years, this finding was no longer significant after adjusting for current severity of depression, nor was it found among patients fully remitted. Thus, by far the most consistent relationship was between rumination and current symptoms. We could not produce unequivocal evidence for rumination being associated with chronicity of depression. Neuroticism predicted rumination, even after accounting for depressive and anxiety symptoms.

A major strength of the study was the life-chart methodology, which enabled us to evaluate the longitudinal course of illness and time-related psychosocial factors. Further strengths included the screening-based medium-sized cohort from a stratified sampling of 1119 patients, structured interviews with SCID-I/P and SCID-II by psychiatrists and the longitudinal study design with a five-year follow-up and a small drop-out rate. Depressive disorders in this primary care cohort were typically major depressive episodes of only mild to moderate severity, but usually recurrent or chronic in nature $[41,42]$. Comprehensive clinical interviews allowed us to analyse the influence of clinical symptoms and other characteristics on rumination; use of life-charts enabled measuring the time spent in different states of depression during the preceding five years. In addition, we carefully evaluated presence of psychiatric comorbidity [41], and in particular, investigated the role of concurrent anxiety, which has more seldom been included in earlier studies [5]. Finally, as rumination was measured at the final interview, there was wide variation in severity of patients' depressive symptoms, ranging from complete remission to severe outpatient depression in some cases [42]. This variation allowed effective analysis of the influence of clinical state factors on rumination.

Several limitations of the study must be noted. First and foremost, response styles were measured only at the end of followup, not at baseline and certainly not before the onset of depressive disorders. Their predictive value, temporal variation and causality of associations remain unknown. Thus, despite the study design otherwise being prospective, with regard to course of rumination it was cross-sectional and retrospective. Course and intra-individual variation of rumination over time remain unknown, and we cannot fully exclude the possibility of reverse causation, i.e. rumination could be influenced or caused by (chronic) depression. Memory biases due to depression are possible. However, to investigate the role of depressive state, we statistically adjusted both the symptoms of depression at five years and the duration of last remission or last MDE, and specifically analysed the subgroup of patients who were not currently depressed. Particularly the latter allowed investigation of the relationship of retrospective chronicity and current response style without significant bias caused by current symptoms. Second, the sampling of the cohort was based on stratified screening of depression to ensure representativeness [41]. However, inclusion of consecutive patients with depressive disorders unavoidably enriches chronicity, as longer duration of depression increases the probability of becoming recruited. Nevertheless, the sample accurately reflects characteristics of actual patients and the actual workload of physicians. Third, despite the moderate sample size, the number of patients in some subgroups remained small, thus increasing risk of type II errors. However, the main findings were robust. Fourth, earlier research has used different versions of the RSQ, which somewhat complicates the comparisons. Fifth, the study was naturalistic and the treatment received, if any, was not controlled. Finally, generalizability of our findings to populations other than urban or suburban primary care patients remains unknown. Generalizability may be limited by occupational or private health care services not being included.

Partly consistent with our hypothesis, rumination was associated robustly with the current state (severity) of depression and with the current severity of anxiety. Based on cross-sectional analysis and lacking information on its preceding course, presence of rumination appears a strongly state-related phenomenon. In contrast, findings for rumination being associated with increased duration of depressive episodes and chronicity remained tenuous. While we found a moderate correlation between duration of MDEs and rumination, this is likely explained by the correlation with severity and duration of depression. In the absence of current depressive symptoms, no such correlation is found. Our findings are partly at odds with earlier research suggesting rumination to put persons at risk for more severe depression and more time spent in MDEs and also new MDEs [40]. Previous research has also found that rumination is more a trait- than a state-related characteristic $[29,46]$. However, the trait-state issue necessitates research with longitudinal designs [9]. While our findings cannot refute the possibility of also a significant trait component, they speak strongly for an influence of the clinical state on the reported degree of rumination.

We found the two subscales for rumination, brooding and pondering, to have slightly different relationships with depression. Both the total score and items of brooding had a consistent strong correlation with depressive symptoms, whereas that association appeared weaker for pondering, in agreement with earlier findings $[47,48]$. Findings of factor analytical studies are not consistent as to whether rumination is unidimensional [12] or comprises two $[8,9,11,49]$ or more $[33,46]$ dimensions. Overall, in addition to RSQ with 22 rumination items, both the rumination-10 and the brooding scales seem to be applicable. Furthermore, our findings regarding correlations with comorbid anxiety and substance use disorders are in accord with the transdiagnostic hypothesis of rumination [27].

The consistent association between neuroticism and rumination in our sample is in accordance with most of earlier literature on non-depressed samples $[8,46,50,51]$. Rumination might act as a general proximal mechanism through which other vulnerability factors affect depression [25,26,46,50,51]. However, even though high neuroticism was associated with high rumination even after controlling for anxiety and depressive symptoms, we found no consistent evidence for rumination causing chronicity. Thus, 
rumination may be exaggerated in the presence of depressive symptoms or possible stressors triggering depression, but whether or not this represents a mechanism by which depression more often becomes chronic warrants investigation via prospective longitudinal studies.

Contrary to what was originally postulated by the response styles theory [52], we found few and small gender differences. Significant differences emerged only in problem-solving, with females scoring higher than males. An explanation for our finding of similar rumination by both men and women may derive from the fact, that we examined primary care patients already suffering from depressive disorders, not gender differences in presence of rumination within the general population. Earlier research has focused on rumination, where females have been noted to ruminate more than males, although the effect sizes have been small [49]. Of other response styles, we found distraction most strongly associate with extraversion. Previous studies have reported distraction to be associated with a lower risk of depression [29,33-35,37], but the findings have been somewhat inconsistent $[39,40]$. We found problem-solving and particularly dangerous activities to be associated not only with severity of depression, but also with several other symptom and psychosocial variables. However, in contrast to the other subscales, the internal consistency of the dangerous activities scale was poor. This subscale has also shown poor validity in other studies [1]. Elucidation of the significance of distraction and problem-solving and the possibility that they comprise an active coping subtype $[5,28]$ warrants investigation in prospective longitudinal studies.

\section{Conclusions}

In this study, we evaluated the relationships between rumination, neuroticism and depression. We found that among primary care patients with depression, the association between neuroticism and rumination was strong. Rumination correlated strongly with current severity of depressive symptoms, but the association with preceding episode duration remained uncertain. These findings are consistent with rumination as a state-related phenomenon, which is also strongly intertwined with traits underlying vulnerability to depression.

\section{Disclosure of interest}

The authors declare that they have no competing interest.

\section{Acknowledgements}

The City of Vantaa, Academy of Finland, Helsinki University Hospital and The Finnish Psychiatric Association have supported this research by grants.

\section{References}

[1] Nolen-Hoeksema S. Responses to depression and their effects on the duration of depressive episodes. J Abnorm Psychol 1991;100:569-82.

[2] Nolen-Hoeksema S, Morrow J, Fredrickson BL. Response styles and the duration of episodes of depressed mood. J Abnorm Psychol 1993;102:20-8.

[3] Nolen-Hoeksema S, Wisco BE, Lyubomirsky S. Rethinking rumination. Perspect Psychol Sci 2008;3:400-24.

[4] Nolen-Hoeksema S. Emotion regulation and psychopathology: the role of gender. Annu Rev Clin Psychol 2012;8:161-87.

[5] Wilkinson PO, Croudace TJ, Goodyer IM. Rumination, anxiety, depressive symptoms and subsequent depression in adolescents at risk for psychopathol ogy: a longitudinal cohort study. BMC Psychiatry 2013;13 [250-244X-13-250]

[6] Nolen-Hoeksema S. The role of rumination in depressive disorders and mixed anxiety/depressive symptoms. J Abnorm Psychol 2000;109:504-11.

[7] McLaughlin KA, Nolen-Hoeksema S. Rumination as a transdiagnostic factor in depression and anxiety. Behav Res Ther 2011;49:186-93.

[8] Roelofs J, Huibers M, Peeters F, et al. Rumination and worrying as possible mediators in the relation between neuroticism and symptoms of depression and anxiety in clinically depressed individuals. Behav Res Ther 2008;46: 1283-9.

[9] Armey MF, Fresco DM, Moore MT, et al. Brooding and pondering: isolating the active ingredients of depressive rumination with exploratory factor analysis and structural equation modeling. Assessment 2009;16:315-27.

[10] Watkins ER. Depressive rumination and co-morbidity: evidence for brooding as a transdiagnostic process. J Ration Emot Cogn Behav Ther 2009;27:160-75.

[11] Treynor W, Gonzales R, Nolen-Hoeksema S. Rumination reconsidered: a psychometric analysis. Cogn Ther Res 2003;27:247-59.

[12] Whitmer AJ, Gotlib IH. Brooding and reflection reconsidered: a factor analytic examination of rumination in currently depressed, previously depressed, and never depressed individuals. Cogn Ther Res 2011;35:99-107.

[13] Pervin LA, Cervone D, John OP. Personality: theory and research, 9th ed., Hoboken, NJ: Wiley; 2005.

[14] Ormel J, Jeronimus BF, Kotov R, et al. Neuroticism and common mental disorders: meaning and utility of a complex relationship. Clin Psychol Rev 2013;33:686-97

[15] Ormel J, Bastiaansen A, Riese H, et al. The biological and psychological basis of neuroticism: current status and future directions. Neurosci Biobehav Rev 2013:37:59-72.

[16] Kendler KS, Neale MC, Kessler RC, et al. A longitudinal twin study of personality and major depression in women. Arch Gen Psychiatry 1993;50:853-62.

[17] Kendler KS, Gatz M, Gardner CO, Pedersen NL. Personality and major depression: a Swedish longitudinal, population-based twin study. Arch Gen Psychiatry 2006;63:1113-20.

[18] Ormel J, Oldehinkel AJ, Vollebergh W. Vulnerability before, during, and after a major depressive episode: a 3-wave population-based study. Arch Gen Psychiatry 2004;61:990-6.

[19] Boyce P, Parker G, Barnett B, et al. Personality as a vulnerability factor to depression. Br J Psychiatry 1991;159:106-14.

[20] Clayton PJ, Ernst C, Angst J. Premorbid personality traits of men who develop unipolar or bipolar disorders. Eur Arch Psychiatry Clin Neurosci 1994;243: 340-6.

[21] Hirschfeld RM, Klerman GL, Lavori P, et al. Premorbid personality assessments of first onset of major depression. Arch Gen Psychiatry 1989;46:345-50.

[22] Jylha P, Melartin T, Rytsala H, Isometsa E. Neuroticism, introversion, and major depressive disorder-traits, states, or scars? Depress Anxiety 2009;26:325-34.

[23] Kendell RE, DiScipio WJ. Eysenck personality inventory scores of patients with depressive illnesses. Br J Psychiatry 1968;114:767-70.

[24] Bagby RM, Parker JDA. Relation of rumination and distraction with neuroticism and extraversion in a sample of patients with major depression. Cogn Ther Res 2001;25:91-102.

[25] Shull AM. Rumination mediates impact of personality on depression. [Honors Thesis] University of Michigan; 2014.

[26] Spasojevic J, Alloy LB. Rumination as a common mechanism relating depressive risk factors to depression. Emotion 2001;1:25-37

[27] Aldao A, Nolen-Hoeksema S, Schweizer S. Emotion-regulation strategies across psychopathology: a meta-analytic review. Clin Psychol Rev 2010;30:217-37.

[28] Knowles R, Tai S, Christensen I, Bentall R. Coping with depression and vulnerability to mania: a factor analytic study of the Nolen-Hoeksema (1991) Response Styles Questionnaire. Br J Clin Psychol 2005;44:99-112.

[29] Just N, Alloy LB. The response styles theory of depression: tests and an extension of the theory. J Abnorm Psychol 1997;106:221-9.

[30] Nolen-Hoeksema S, Parker LE, Larson J. Ruminative coping with depressed mood following loss. J Pers Soc Psychol 1994:67:92-104.

[31] Nolen-Hoeksema S, McBride A, Larson J. Rumination and psychological distress among bereaved partners. J Pers Soc Psychol 1997;72:855-62.

[32] McEvoy PM, Watson H, Watkins ER, Nathan P. The relationship between worry, rumination, and comorbidity: evidence for repetitive negative thinking as a transdiagnostic construct. J Affect Disord 2013;151:313-20.

[33] Lam D, Smith N, Checkley S, et al. Effect of neuroticism, response style and information processing on depression severity in a clinically depressed sample. Psychol Med 2003;33:469-79.

[34] Bagby RM, Rector NA, Segal ZV, et al. Rumination and distraction in major depression: assessing response to pharmacological treatment. J Affect Disord 1999:55:225-9.

[35] Donaldson C, Lam D. Rumination, mood and social problem-solving in major depression. Psychol Med 2004;34:1309-18.

[36] Kasch KL, Klein DN, Lara ME. A construct validation study of the Response Styles Questionnaire Rumination Scale in participants with a recent-onset major depressive episode. Psychol Assess 2001;13:375-83.

[37] Kuehner C, Huffziger S. Response styles to depressed mood affect the longterm course of psychosocial functioning in depressed patients. J Affect Disord 2012;136:627-33.

[38] Kuehner C, Huffziger S. Factors predicting the long-term illness course in a cohort of depressed inpatients. Eur Arch Psychiatry Clin Neurosci 2013;263:413-23.

[39] Schmaling KB, Dimidjian S, Katon W, Sullivan M. Response styles among patients with minor depression and dysthymia in primary care. J Abnorm Psychol 2002;111:350-6.

[40] Teismann T, Steinfeld B, Willutzki U, Michalak J. Rumination and distraction: selected findings related to the response styles theory. Psychother Psychosom Med Psychol 2011;61:126-32.

[41] Vuorilehto M, Melartin T, Isometsa E. Depressive disorders in primary care: recurrent, chronic, and co-morbid. Psychol Med 2005;35:673-82.

[42] Riihimaki KA, Vuorilehto MS, Melartin TK, Isometsa ET. Five-year outcome of major depressive disorder in primary health care. Psychol Med 2011;1-11. 
[43] Nolen-Hoeksema S, Morrow J. A prospective study of depression and posttraumatic stress symptoms after a natural disaster: the 1989 Loma Prieta Earthquake. J Pers Soc Psychol 1991;61:115-21.

[44] Eysenck H, Eysenck S. Manual of the Eysenck Personality Inventory. London: University of London Press Ltd; 1964.

[45] Floderus B. Psychosocial factors in relation to coronary heart disease and associated risk factors. Nordisk Hygienisk Tidskrift 1974;Suppl. 6: $1-148$.

[46] Roberts JE, Gilboa E, Gotlib IH. Ruminative response style and vulnerability to episodes of dysphoria: gender, neuroticism, and episode duration. Cogn Ther Res 1998;22:401-23.

[47] Miranda R, Nolen-Hoeksema S. Brooding and reflection: rumination predicts suicidal ideation at 1-year follow-up in a community sample. Behav Res Ther 2007;45:3088-95.
[48] Surrence K, Miranda R, Marroquin BM, Chan S. Brooding and reflective rumination among suicide attempters: cognitive vulnerability to suicidal ideation. Behav Res Ther 2009;47:803-8.

[49] Johnson DP, Whisman MA. Gender differences in rumination: a meta-analysis. Pers Individ Dif 2013;55:367-74.

[50] Muris P, Roelofs J, Rassin E, et al. Mediating effects of rumination and worry on the links between neuroticism, anxiety and depression. Pers Individ Dif 2005;39:1105-11.

[51] Van Loey NE, Oggel A, Goemanne AS, et al. Cognitive emotion regulation strategies and neuroticism in relation to depressive symptoms following burn injury: a longitudinal study with a 2-year follow-up. J Behav Med 2014;37: 839-48.

[52] Nolen-Hoeksema S. Sex differences in unipolar depression: evidence and theory. Psychol Bull 1987;101:259-82. 